\title{
ENTREVISTA
}

\section{POLÍTICAS PÚBLICAS LGBT EM TEMPOS ADVERSOS ENTREVISTA COM MARINA REIDEL ${ }^{1}$}

\author{
Cleyton Feitosa, Universidade de Brasília $(\mathrm{UnB})^{2}$
}

Ocorrida em 16 de fevereiro de 2018 no $9^{\circ}$ andar do edifício Parque Cidade Corporate, onde fica localizado o Ministério dos Direitos Humanos, a entrevista com Marina Reidel, atual Diretora de Promoção dos Direitos de Lésbicas, Gays, Bissexuais, Travestis e Transexuais (LGBT) do Governo Federal, abordou, de um lado, a sua trajetória política permeada por experiências de trânsito entre a academia, o ativismo e a gestão e, de outro, uma discussão mais ampla sobre as políticas públicas LGBT no atual cenário social e político do Brasil.

Marina é gaúcha, natural de Montenegro/RS, professora da rede pública de ensino e mulher trans. É licenciada em Educação Artística pela Universidade Feevale, Especialista em Psicopedagogia Institucional pela Universidade Castelo Branco e Mestra em Educação pela Universidade Federal do Rio Grande do Sul (UFRGS) sob orientação do Professor Doutor Fernando Seffner de quem sempre fala com um misto de carinho e admiração. Militante ativa e orgânica, acumula experiências de representação política em instituições participativas de âmbito nacional a exemplo do Conselho Nacional de Combate à Discriminação e Promoção dos Direitos de Lésbicas, Gays, Bissexuais, Travestis e Transexuais (CNCD/LGBT) e do Comitê Técnico de Cultura LGBT do Ministério da Cultura. Compôs a Diretoria da Associação Brasileira de Estudos da Homocultura (ABEH), na qual representou a entidade no CNCD/LGBT.

A partir das diversas interações socioestatais estabelecidas com o governo estadual do Rio Grande do Sul e federal, foi convidada a assumir a gestão de políticas públicas LGBT tanto na Secretaria de Justiça e Direitos Humanos do seu estado de origem quanto na Coordenação-Geral de Promoção dos Direitos de LGBT no recém-

\footnotetext{
${ }^{1}$ Revisão Textual de Bruna Andrade Irineu.

2 Doutorando em Ciência Política pela Universidade de Brasília - UnB. Mestre em Direitos Humanos pela Universidade Federal de Pernambuco - PPGDH/UFPE. Licenciado em Pedagogia pela Universidade Federal de Pernambuco/Centro Acadêmico do Agreste - UFPE/CAA. Pesquisador dos grupos de pesquisa (CNPq) RESOCIE Repensando as Relações entre Sociedade e Estado (Doutorado), DIVERSIONES - Direitos Humanos, Poder e Cultura em Gênero e Sexualidade (Mestrado) e Movimentos Sociais, Educação e Diversidade na América Latina (Graduação).
}

$\begin{array}{lllll}\text { Vol 01, } & \text { N. } & 02 & - & \text { Abr.-Jun., }\end{array}$

http://www.revistas.unilab.edu.br/index.php/rebeh/index 
criado Ministério da Justiça e da Cidadania à época chefiado por Alexandre de Moraes e Flávia Piovesan logo após o impeachment de Dilma Rousseff e o início do Governo Michel Temer.

Mas a conjuntura adversa e o receio de críticas não impediu Marina de ocupar o principal posto de execução das políticas LGBT no Brasil e exercer o fenômeno pelo qual alguns cientistas políticos tem chamado de "ativismo institucional". Deste modo, explorei nesse diálogo sua trajetória individual enfatizando essas experiências políticas como um exemplo das complexas conexões entre o Movimento LGBT e o Estado que demonstra, no caso brasileiro, intenso trânsito e fluxo de ativistas e movimentos sociais entre a sociedade civil e o Estado dando feição à construção democrática do nosso país.

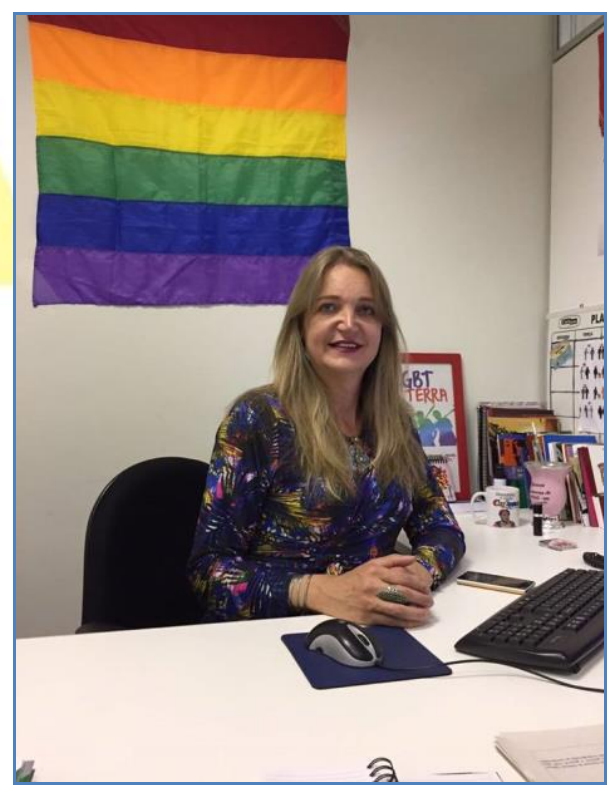

Figura 1 - Marina Reidel, Diretora LGBT, em seu gabinete no Ministério dos Direitos Humanos. Fevereiro de 2018.

Cleyton: Você poderia nos falar sobre a sua trajetória de vida? Cidade, contexto familiar, infância, essa parte mais inicial da tua vida.

\footnotetext{
${ }^{3}$ Fornece inteligibilidade a um tipo de conexão específica entre Estado e movimentos que é expressa pela ocupação de cargos oficiais e não eletivos no Estado por atores oriundos dos movimentos sociais. Mais do que envolver o recolhimento de agendas dos movimentos sociais por atores do Estado, o ativismo institucional implica a imbricação de projetos políticos que, muitas vezes mediada pelo pertencimento partidário, possibilita a ocupação de cargos em diferentes níveis na burocracia pública - sobretudo os temporários de livre nomeação - por atores dos movimentos sociais que buscam de forma ativa imprimir mudanças em setores de políticas públicas com as quais são comprometidos antes mesmo de sua inserção no Estado (CAYRES, 2017, p. 83).
}

Vol 01, N. $02 \quad-\quad$ Abr.-Jun., 
Marina: Eu vim da cidade do interior, de Montenegro. Uma cidade pequena na região do interior do Rio Grande do Sul próxima a Porto Alegre. De família... Origem, descendência alemã, família pobre, cinco filhos, sendo que eu era a caçula. Meu pai e minha mãe sempre traziam o trabalho como uma característica muito forte, por ser de origem alemã e sempre teve a característica do caráter também. De religiões, mesmo diferentes, porque meu pai era católico e minha mãe era protestante, mas tinha essa coisa de ir à igreja e era muito forte. Meu pai era alcóolatra, então isso, às vezes, dificultava um pouco os diálogos e as questões que eram desde a questão familiar até essas questões que hoje a gente fala muito, sobre sexualidade e gênero. Naquela época não falavam essas questões, então eu vim deste lugar. Logo eu fui estudar e fazer o curso normal porque eu queria ser professora e logo comecei na carreira do magistério público. Com 18 anos eu já era professora, fiz concurso público e já dava aula. E depois desses processos todos de me colocar neste lugar de profissional, de estar estabilizada, de ter uma garantia de trabalho e de um concurso foi que eu assumi minha identidade de gênero.

Cleyton: Quero te perguntar sobre sua escolarização. Esse período da escola, da Educação Básica, do Ensino Fundamental e Médio. Que lembranças te vem à memória?

Marina: As lembranças não são muito positivas porque desde a entrada na escola até sair do Ensino Fundamental sempre eram marcadas por violência, por agressão, pelo silêncio dos professores. "Porque eu era assim, então eu teria que responder por eu ser assim", que era essa identidade não assumida. Então, as experiências sempre foram marcadas por esse processo. Quando eu saí do Ensino Fundamental fui para o Ensino Médio, que já era um curso normal de formação de professores, naquela época era ainda um curso que te habilitava a ser professora de ensino fundamental, séries iniciais, então eu sabia que lá naquele lugar só existiriam meninas porque também era uma condição de eu ir pra uma escola de Ensino Médio. Eu estive duas semanas numa escola técnica e eu não consegui ficar. Eu não consegui por conta desse processo. Era a noite e muito complicado por conta da violência, principalmente com os rapazes ou com os meninos na época. Então as lembranças que eu tenho da escola eram essas. Por outro lado, tinha um desejo de querer estar nesse lugar e participar desses espaços como Grêmio Estudantil, de participar de atividades culturais da escola, sempre tinha a intenção de me $\begin{array}{llllllllll}\text { Vol } & 01, & N & 02 & - & \text { Abr.-Jun., } & 2018 & \text { ISSN } & \text { 2595-3206 }\end{array}$ http://www.revistas.unilab.edu.br/index.php/rebeh/index 
envolver nos jogos estudantis, mesmo não gostando de Educação Física, pois era um trauma da Educação Física porque eu era obrigada a jogar futebol. Depois com a onda do voleibol masculino surgiu uma oportunidade de jogar porque eu tinha uma boa estatura e sempre era requisitada pra jogar nesses espaços também.

\section{Cleyton: Ouvindo algumas de suas palestras, você sempre enfatiza a sua transição} de gênero no momento em que atuava como professora de uma escola de Educação Básica. Pode contar essa história aqui?

Marina: Na verdade, quando eu saí dessa cidade e fui pra uma cidade maior, que era Porto Alegre, eu comecei a perceber que eu era uma pessoa entre milhares, quer dizer, eu não era mais "a" pessoa que era vista como: o professor, fulano de tal, daquela escola tal, daquela cidade tal. Eu era qualquer um na multidão. Qualquer uma. Você começa a perceber que, a partir do momento que você fecha a porta do seu apartamento, ninguém fica te vigiando, controlando sua vida e começa a se dar conta de que isso é possível. $\mathrm{Na}$ época que eu assumi minha identidade de gênero dentro da escola também eu vi que era possível, nós tínhamos já esses movimentos muito mais próximos, nós tínhamos um governo que era favorável, tanto a nível estadual quanto a nível federal. Já tinha começado muitos processos de resoluções, de leis que poderiam me garantir, também, enquanto profissional, que eu não ia sofrer nenhum tipo de preconceito naquele lugar. Talvez eu até poderia ter sido retirada da escola e jogada numa biblioteca, mas eu sabia que ia estar garantido meu direito enquanto profissional. Porque como eu já era sozinha e precisava me manter e sobreviver nesse espaço, eu também tinha que preservar meu local de trabalho como uma garantia de vida. Então foi isso.

Quando eu fiz esse processo de transformação, na verdade eu só assumi aquilo que estava sempre ligado a mim, mas que eu não conseguia, antes, expressar ou colocar essa identidade. E aí foi um pouco tranquilo porque no estado do Rio Grande do Sul já existiam algumas leis que favoreciam essa questão da discriminação, do preconceito, isso também favoreceu aquele processo. Também já começavam as discussões dentro do próprio tema da sexualidade e gênero, Brasil Sem Homofobia ${ }^{4}$, então alguns projetos de ONGs [Organizações Não-Governamentais] procuraram a escola para parcerias e eu

\footnotetext{
${ }^{4}$ Programa lançado em 2004 pelo Governo Lula.
}

$\begin{array}{lllllllll}\text { Vol } & 01, & N & 02 & - & \text { Abr.-Jun., } & 2018 & \text { ISSN } & \text { 2595-3206 }\end{array}$ http://www.revistas.unilab.edu.br/index.php/rebeh/index 
me inteirei. Quer dizer, naquele momento e naquele lugar assumir a identidade era positivo. Pra minha surpresa, os alunos e pais foram super tranquilos. Não tive problema nenhum. Mesmo dando aula de quinta à oitava série, pois era professora de Artes na época, eu não tive nenhum problema com isso. O que teve mais dificuldades, realmente, foi a postura dos colegas, das professoras, dos professores, de realmente me reconhecer como a profissional competente, porém com uma outra identidade, então isso foi uma dificuldade que surgiu, mas que, na verdade, a diretora e algumas pessoas apoiaram para que não houvesse o preconceito maior ainda. Mas eu senti sempre que havia aquele olhar do: "Bom, e agora? O que ela vai fazer quando fechar a porta da sala de aula? Como serão as aulas e se isso não vai virar só libertinagem e putaria, enfim...”. Então talvez isso tenha sido o maior temor desse padrão, que a gente fala, de heteronormatividade de que as coisas tem que ser conforme as regras, da escola ou, enfim, as regras da sociedade.

\section{Cleyton: E como foi sua entrada no Movimento LGBT?}

Marina: Acredito que foi através desse lugar ao assumir minha identidade, de participar dessas atividades junto à uma ONG que temos em Porto Alegre, o SOMOS [SOMOS Comunicação, Saúde e Sexualidade] $]^{5}$. Na verdade, eles procuraram a escola para oferecer o curso de capacitação para professores em sexualidade e gênero porque o objetivo era esse, era a formação de professores. E aí eles me descobriram na escola. Então, na verdade, o SOMOS, através das pessoas que estavam naquela época, logo me identificaram como uma trans. Mesmo eu não me colocando naquele lugar. Eu comecei a participar das atividades do SOMOS e logo fui convidada a falar sobre as minhas experiências em diversos lugares.

Logo em seguida eu fui para outro curso de uma outra ONG, do Nuances [Nuances Grupo Pela Livre Expressão Sexual] ${ }^{6}$, que é uma das ONGs mais antigas do Rio Grande do Sul e que também oferecia cursos de capacitação porque eu também teria que me entender e participar desses lugares para poder conhecer um pouco mais. Ter um pouco mais de conhecimento sobre isso num todo. Então eu comecei a participar e não tinha

\footnotetext{
${ }^{5}$ Para conhecer o SOMOS, visite: http://somos.org.br/. Acesso em: 19 de fevereiro de 2018.

${ }^{6}$ Para conhecer o Nuances, visite: https://www.facebook.com/nuanceslgbts/. Acesso em: 19 de fevereiro de 2018.

$\begin{array}{lllllllll}\text { Vol 01, } & \text { N. } & 02 & - & \text { Abr.-Jun., } & 2018 & \text { ISSN } & \text { 2595-3206 }\end{array}$ http://www.revistas.unilab.edu.br/index.php/rebeh/index
} 
relação com nenhuma ONG específica e circulava em diversos lugares, tanto nas universidades ou em encontros sempre com o foco da educação. Depois eu fui conhecer a Igualdade [Igualdade - Associação de Travestis e Transexuais do Rio Grande do Sul] ${ }^{7}$ e Marcelly Malta através do Nuances e sempre foi assim através de um e de outro você começa a circular.

Eu conheci mesmo o Movimento Trans quando eu vim participar de um congresso de HIV/AIDS e Hepatites Virais aqui em Brasília em 2010 e aí estavam todas reunidas, mas também foi no mesmo período que eu apareci na novela, naquela vinheta de "Viver a Vida" a novela da Globo ${ }^{8}$ que abordava sobre superações. Ali eu também fiquei conhecida. Foi muito simultâneo, todas as atividades, tanto do Movimento, quanto da questão da educação. Então só em 2010 que eu me dei conta de que só contar a história não dava mais, quer dizer, eu precisava ir além. Aproveitando as oportunidades de novo e voltei a estudar entrando em 2011 no Mestrado em Educação com essas discussões de sexualidade e gênero.

Cleyton: A próxima pergunta é justamente sobre sua vida acadêmica. Qual é a sua formação e quais são suas principais agendas de pesquisa?

Marina: Eu fiz magistério no Ensino Médio, eu fiz graduação em Artes Visuais com habilitação em Artes Plásticas e Pós-Graduação [Especialização Lato Sensu] em Psicopedagogia. Depois, concluí o Mestrado na área de Educação, Sexualidade e Relações de Gênero na Universidade Federal do Rio Grande do Sul em 2013. Na verdade tenho várias frentes, mas a minha pesquisa, na época, era a temática e a problemática das professoras trans na educação, assim como eu. Hoje as pessoas falam sobre vários temas e o meu foco é voltar de novo à academia para o Doutorado e trabalhar com crianças trans. A criança transgênero, a criança transexual, a criança travesti, enfim, pensar de que modo essas expressões de gênero na criança refletem na educação. Penso que temos poucas pesquisas nessa área então pretendo buscar este tema como foco principal e seus indicadores no processo de aprendizagem pelo viés do olhar

\footnotetext{
${ }^{7}$ Para conhecer a Igualdade, visite: http://www.aigualdaders.org/. Acesso em: 19 de fevereiro de 2018.

${ }^{8}$ A novela Viver a Vida da TV Globo se destacou por apresentar na trama uma protagonista negra (Taís Araújo) e trazer ao final de cada capítulo histórias reais de superação. Para maiores informações sobre a novela, consulte: http://memoriaglobo.globo.com/programas/entretenimento/novelas/viver-a-vida.htm. Acesso em: 19 de fevereiro de 2018.

\begin{tabular}{llllll|lll} 
Vol & 01, & $N$ & 02 & - & Abr.-Jun., & 2018 & ISSN & 2595-3206
\end{tabular} http://www.revistas.unilab.edu.br/index.php/rebeh/index
} 
da criança agora, de que forma elas são vistas na escola, como são os arranjos e os desafios para aprender. Assim como temos adolescentes, temos crianças. Acredito nessa proposta para a próxima etapa no Doutorado se selecionada.

Cleyton: Ainda sobre o seu Mestrado. Vi um pouco da dissertação, li alguns artigos seus, inclusive em coautoria com o professor Fernando Seffner, e você fala em uma Pedagogia do Salto Alto. O que seria essa Pedagogia do Salto Alto na sua compreensão?

Marina: Foi uma metáfora criada para problematizar um pouco a questão do feminino, de como a professora se coloca no lugar do feminino, do salto e que o mesmo tem essa representatividade em relação a questão da Pedagogia mesmo, o ensinar e o aprender, enfim, das relações que se estabelecem e de que forma isso se daria nesse contexto.

Bom, nós estamos falando especificamente de quem? De pessoas que usam salto e o atravessamento da educação como um foco. No dia da minha defesa o Professor Fernando Seffner citou que a Sandra Corazza, que é uma grande pesquisadora na área da educação, usa em seus títulos metáforas com simbologias muito ricas para reflexão. E ele ainda brincou porque ela estava na plateia no dia da minha defesa. Ele disse assim: "e casualmente ela ainda é da tua cidade".

A partir dessa proposta até hoje exploro este título para escrever alguns artigos e resgato a Pedagogia do Salto Alto. Na época, foi muito bem aceito, inclusive pelo professor Fernando quando ele disse: “Ótimo título! Adorei!”. Rompi um pouco com os padrões utilizados na academia. A escrita foi na primeira pessoa, ou seja, eu me coloquei muitas vezes nesse lugar de pesquisadora, mas também da pessoa trans e professora. Claro que não era eu o objeto da pesquisa, mas tinha muito a ver com as relações estabelecidas na minha dissertação. Em todos os momentos brinquei com as temáticas do feminino, da educação, enfim, todo esse jogo que podemos criar pra quebrar um pouco esses padrões acadêmicos que vemos o tempo inteiro.

Cleyton: Sei que você teve uma experiência pregressa de gestora estadual LGBT no Rio Grande do Sul. Qual cargo você exerceu e que funções desempenhou?

$\begin{array}{lllllllll}\text { Vol } & 01, & N & 02 & - & \text { Abr.-Jun., } & 2018 & \text { ISSN } & \text { 2595-3206 }\end{array}$ http://www.revistas.unilab.edu.br/index.php/rebeh/index 
Marina: Quando eu entrei no Mestrado tive que me afastar da escola, das rotinas de horários, turnos que você tem que cumprir e muitas vezes havia conflito de agenda por conta das disciplinas, das aulas que eu tinha que fazer. Fui trabalhar na Secretaria de Educação, fiquei um tempo, um ano na Secretaria de Educação e logo fui convidada para trabalhar no município de Canoas como gestora municipal com a pauta da Coordenação da Diversidade. Fui convidada por algumas pessoas daquele município justamente fazendo um trabalho voltado a reinserção das trans e as travestis que não frequentavam aquele lugar. $\mathrm{Na}$ verdade, o objetivo era fomentar a política com a participação social e fazer essa relação realmente de aproximação porque muitas, como a gente sabe, não procuram os espaços públicos por medo, por receio, por pensar que aquilo não é um lugar onde elas vão estar contempladas.

Bom, eu trabalhei um ano lá e aí logo em seguida eu tive problemas com minha cedência. Tive que retornar para o estado e fui convidada pra trabalhar por indicação do próprio Movimento LGBT do Rio Grande do Sul como Coordenadora Estadual da Política LGBT. Fiquei dois anos na gestão estadual articulando a política. Consegui organizar o Conselho Estadual [LGBT] e a duras penas a $3^{\text {a }}$ Conferência Estadual LGBT. A luta era por fortalecimento da política no estado, principalmente nos municípios do interior onde existe o preconceito e não existe um mecanismo que possa atender as necessidades. Hoje eu vejo que o trabalho gerou frutos porque temos gestores LGBT nos municípios, alguns espaços como os ambulatórios trans ou ambulatórios de saúde TT em alguns municípios. Quer dizer, políticas que foram dialogadas lá em 2014 até 2016 e que hoje vemos alguns resultados.

Claro que tem uma certa dificuldade. Tem municípios que romperam com a pauta LGBT nas gestões municipais mas tiveram outros que, para a minha surpresa, construíram políticas, seja através de gestão, assessoria ou conselhos. Aos poucos conseguimos manter a pauta LGBT nesse cenário, inclusive, com todas as dificuldades de troca de governo.

Cleyton: Outra vivência de interesse para essa entrevista foi a de integrante do Conselho Nacional de Combate à Discriminação e Promoção dos Direitos de LGBT (CNCD/LGBT). Poderia compartilhar como foi essa experiência de representação política?

$\begin{array}{llllllllll}\text { Vol } & 01, & N . & 02 & - & \text { Abr.-Jun., } & 2018 & \text { ISSN } & \text { 2595-3206 }\end{array}$ http://www.revistas.unilab.edu.br/index.php/rebeh/index 
Marina: Eu não tinha entidade ativista até 2012, pois eu era uma ativista e depois uma gestora que dialogava com todas as redes. Quando eu entrei no Mestrado, participei de um Encontro da ABEH [Associação Brasileira de Estudos da Homocultura] ${ }^{9}$ em Salvador, 2012. Neste evento o professor Fernando Seffner foi convidado a assumir a Diretoria e reuniu diversos pesquisadores gaúchos e compôs a chapa votada em plenária para o biênio 2013-2015. Então vim fazer parte da ABEH em 2013 e logo em seguida, como Fernando tinha dificuldade pra participar das reuniões do $\mathrm{CNCD}$ porque realmente a agenda dele era 3 vezes maior que a minha, sugeriram meu nome para ser titular no Conselho.

Como representante no Conselho fiquei de 2013 a 2015 e novamente, a convite do professor Anderson Ferrari, permaneci na gestão que seria de 2015 a 2017. No entanto, me afastei em 2016 para assumir o cargo de Diretora da pasta LGBT do Ministério dos Direitos Humanos.

Foi um processo de aprendizagem onde você vive diversas disputas políticas e aprende a trabalhar com esse coletivo que é diverso. Você faz um diálogo constante dentro da sociedade civil, apresenta suas propostas, disputa de forma democrática a aprovação de documentos e manifesta o que determinados grupos estão trabalhando fora também deste espaço como na academia, por exemplo. Foram alguns espaços construídos. Propomos a $3^{\mathrm{a}}$ Conferência como espaço democrático de direito e de aprendizado, documentos elaborados e discutidos no plenário, resoluções conjuntas e próprias como dispositivo de manutenção da pauta e dos atravessamentos. Apesar das dificuldades encontradas até hoje é um local que mantém a resistência do controle social.

A ABEH é uma associação que discute nesse lugar da academia, mas que também considera o lugar do movimento social até porque muitos pesquisadores que estão na pesquisa, que estão na $\mathrm{ABEH}$, já foram, já passaram por esse lugar do ativismo em algum momento.

\footnotetext{
${ }^{9}$ Para conhecer a Associação Brasileira de Estudos da Homocultura, visite a página: http://abeh.org.br/. Acesso em: 19 de fevereiro de 2018.

$\begin{array}{lllllllll}\text { Vol } & 01, & N & 02 & - & \text { Abr.-Jun., } & 2018 & \text { ISSN } & \text { 2595-3206 }\end{array}$ 
Cleyton: Como surgiu o convite para assumir a Coordenação-Geral de Promoção dos Direitos de LGBT do então Ministério da Justiça e da Cidadania? Houve algum receio da sua parte em compor o governo num contexto de uma grave crise política?

Marina: Quando eu vim pra cá na reunião do CNCD/LGBT de julho de 2016 fui pega de surpresa com o convite do então diretor Frederico Coutinho. Fui chamada para conversar sobre essa possibilidade. Eu me assustei um pouco porque não é só uma mudança de um estado para outro, mas era naquele cenário e no contexto difícil após o impeachment. Eu sabia que seria acusada de golpista, no entanto, aceitei o desafio já que era uma mudança e um novo aprendizado, agora na esfera federal.

O receio de assumir, mas ao mesmo tempo, como foi colocado, é: quem assumiria se eu não assumisse esse lugar? E foi uma indicação, inclusive, de algumas pessoas do Conselho na época. Quer dizer, meu nome foi respaldado pelo próprio Conselho, foi respaldado por algumas pessoas do Conselho, inclusive da própria Vice-Presidenta à época, a Roselaine Dias da Liga Brasileira de Lésbicas ${ }^{10}$, que sugeriu quando foi consultada pela Secretária Flávia [Piovesan]. E ela sabendo da minha experiência no estado e meu diálogo tranquilo com a sociedade civil que sempre tive tanto lá quanto aqui, talvez seria a pessoa indicada naquele momento para o cargo. Não que eu seria a salvadora da pátria, mas talvez seria o melhor momento pra fazer e manter o que se estabeleceu como diálogo entre a sociedade civil e o governo. Você mesmo se colocando como gestora, você reconhece que esse lugar da sociedade civil sempre foi o que manteve toda a política no Brasil em relação à população LGBT. Quem sempre fez a política andar, quem sempre avançou e provocou foi a sociedade civil.

Cleyton: E de lá pra cá houve muitas mudanças: a Coordenação-Geral se transformou em Diretoria LGBT e saiu do Ministério da Justiça e da Cidadania para o Ministério dos Direitos Humanos. Também mudaram os atores políticos centrais: saíram Alexandre de Moraes e Flávia Piovesan e entrou Luislinda Valois. Que impactos essas alterações exerceram sobre as políticas públicas LGBT internamente?

\footnotetext{
${ }^{10}$ Para conhecer a Liga Brasileira de Lésbicas, visite: https://lblnacional.wordpress.com/. Acesso em 19 de fevereiro de 2018.

$\begin{array}{llllllllll}\text { Vol } & 01, & N . & 02 & - & \text { Abr.-Jun., } & 2018 & \text { ISSN } & \text { 2595-3206 }\end{array}$ http://www.revistas.unilab.edu.br/index.php/rebeh/index
} 
Marina: A Secretária Flávia sempre respeitou muito a pauta e sempre levou como um dos carros-chefes dessa Secretaria e da mesma forma com a própria Ministra Luislinda quando coloca a necessidade da criação de uma Secretaria Nacional LGBT. Penso que a pauta e essas pessoas, sempre respeitaram e mantiveram, sem retrocessos. Inclusive com a promoção de um status melhor, que é de Diretoria. Não podemos dizer que houve retrocesso. Houve a manutenção da pauta sim, desde a mudança, de um governo para o outro e a expectativa de que pudesse ainda ser melhor ou que será melhor se conseguirmos avançar e construir algumas políticas de Estado. Claro que tem toda uma estrutura, tem toda uma nova perspectiva de financiamento, de recursos, de status, enfim, de mudança e pode ser positivo nesse lugar, nesse momento que vivemos no cenário como um todo. Seja no Congresso, seja nos estados, nos municípios, nas Câmaras, enfim, todos os lugares onde a gente vai ter a temática LGBT como um retrocesso. À nível federal conseguimos manter e avançar algumas questões. E é um desafio.

Cleyton: Quais são as demandas e reivindicações que são apresentadas por redes e ativistas do movimento social à Diretoria LGBT? Que respostas tem sido dadas?

Marina: As demandas geralmente são no sentido de apoio, apoio institucional, apoio financeiro porque há muita produção. Vejo que a sociedade civil, assim como as universidades tem se organizado de uma forma e consegue produzir muita coisa, seja produção científica, social, cultural, material, evento, enfim. Então isso demanda também a necessidade de pensar em apoio, mesmo que institucionalmente, mas que de certa forma deve responder a uma série de demandas na questão financeira mesmo com cortes e etc. Esse é um desafio real, mas de que forma vamos reestruturar? Porque nós também temos hoje, por outro lado, ONGs abandonadas e que estão fragilizadas por uma série de questões. Falta de espaço físico, falta de recurso, falta de avançar com projetos, por conta de editais reduzidos ou que não existem mais. Nessas demandas temos que usar a criatividade como ponto forte mas só isso não dá conta e não responde às mesmas que lutam no dia a dia.

A demanda hoje é grande. Temos várias redes nacionais, estaduais e municipais que tem articulações mas que às vezes falta minimamente um apoio até para se manter. Nós $\begin{array}{llllllllll}\text { Vol } & 01, & N & 02 & - & \text { Abr.-Jun., } & 2018 & \text { ISSN } & \text { 2595-3206 }\end{array}$ http://www.revistas.unilab.edu.br/index.php/rebeh/index 
tínhamos antes os Centros de Referência LGBT que foi um projeto anterior, que a Ministra Maria do Rosário incentivava as criações desses espaços, mas não houve a manutenção por conta dos estados que não mantiveram. Porque a ideia era dar um impulso, através de recursos do governo federal para a criação de Centros que poderiam atender as demandas também e esses fluxos que se tem. No entanto, os estados também estão sucateados ou falidos. A grande maioria hoje não tem recurso sequer pra pagar a folha de pagamento como é o meu estado de origem, por exemplo. Você manter um mecanismo desses, eles vão dizer que não tem condições. Porque direitos humanos de LGBT muitas vezes são colocados em segundo plano. Pensar em uma rede seria o ideal dentro de um Sistema Nacional LGBT ${ }^{11}$, como era a ideia do Brasil Sem Homofobia. Mas o problema é esse: de que forma a gente vai articular uma rede nacional se a gente não consegue nem fomentar alguns espaços ainda, entendeu? Por conta da questão financeira mesmo e do preconceito institucional.

\section{Cleyton: Tomando essa entrevista também como o que chamamos na Ciência} Política de accountability, ou seja, como uma prestação de contas, quais foram as principais iniciativas, ações e políticas desenvolvidas para a população LGBT na sua gestão?

Marina: Inicialmente pensamos num plano curto e objetivo que desse conta das necessidades mais urgentes. Uma delas mais a curto prazo foi a campanha $\mathrm{LGBT}^{12}$ concluída como lançamento do experimento social, que foi o vídeo. A ideia da campanha e a divulgação dela, levar ela para outros lugares porque não adianta você fazer a campanha e ficar aqui dentro, quer dizer, tem que espalhar por esse Brasil todo. A construção do Pacto Contra a Violência LGBTfóbica porque o enfrentamento da violência no dia a dia é uma pauta constante dessa Diretoria. Nós temos uma consultoria para levar o Pacto para os estados e dialogar na adesão mesmo com todas as dificuldades orçamentárias. Temos trabalhado com os Relatórios de Violência ${ }^{13}$ fazendo

\footnotetext{
11 Para maiores informações sobre o Sistema Nacional de Promoção de Direitos e Enfrentamento à Violência contra LGBT, consultar: https://agencia-brasil.jusbrasil.com.br/noticias/100583510/governolanca-sistema-nacional-lgbt-para-integrar-politicas-contra-o-preconceito. Acesso em: 19 de fevereiro de 2018.

12 Marina se refere à campanha institucional "Deixe Seu Preconceito de Lado" que pode ser consultada em: http://www.mdh.gov.br/campanha-lgbt/pecas-campanha-lgbt. Acesso em: 19 de fevereiro de 2018.

${ }^{13}$ Entre os anos de 2011 a 2013, a SDH lançou Relatórios de Violência Homofóbica tendo como base de dados principal os números de denúncias reportadas ao Disque 100 (Disque Direitos Humanos). Com as constantes trocas de gestores da Coordenação LGBT, a Secretaria interrompeu o lançamento dos $\begin{array}{llllllll}\text { Vol 01, } & \text { N. } & 02 & - & \text { Abr.-Jun., } & 2018 & \text { ISSN } & \text { 2595-3206 }\end{array}$ http://www.revistas.unilab.edu.br/index.php/rebeh/index
} 
essa articulação toda com os outros Ministérios. Articulação com o CNCD/LGBT, a manutenção desse mecanismo. Nós criamos a Comissão dos Gestores que já era um Comitê que existia anteriormente, mas simplificamos um pouco ele por questões orçamentárias também, mas não deixar que a pauta, pra manter o diálogo também com esses representantes dos gestores. Trouxemos os gestores para o diálogo e esse é nosso papel, de articular o tempo inteiro para que a pauta esteja presente. A questão da saúde que sempre foi a porta de entrada, mas como estamos dentro da saúde? De que forma estamos dialogando com o Ministério da Saúde, com o Departamento de AIDS, com essas outras autarquias, ENAP [Escola Nacional de Administração Pública], ANAC [Agência Nacional de Aviação Civil], sempre levando a pauta de alguma forma. Seja a discussão do nome social, seja a questão do enfrentamento da violência, de que forma podemos divulgar a campanha, buscando articular o tempo inteiro.

Além disso, temos pensado para o final da gestão em criar um compêndio de ações afirmativas através de um edital, de trazer realmente através de um compêndio, um livro, enfim, pensar minimamente o que tem sido feito no Brasil com essa pauta. Aonde podemos ver ações que são positivas? Seja nas universidades, na sociedade civil, governos, quer dizer, organizar esse material um pouco mais. Eu vejo que nós temos muitos gestores que pedem o tempo todo: "socorro, eu preciso de uma ideia", não que vai copiar, mas precisa ter. Teve algum estado que já fez isso? Nós temos feito diálogo constante com esses organismos internacionais para captar recursos. Os próprios recursos conseguimos por meio de consultorias e assim dar conta de alguns objetivos propostos. À curto prazo é isso, à longo prazo ou médio prazo, acho que é essa ideia do Pacto que vai depender da adesão dos estados, um Pacto entre a União e os estados. Claro que os municípios poderão articular depois com os estados, mas a ideia é pensar de que forma vai se articular. Nosso próximo desafio é preparar o caminho para a próxima Conferência Nacional LGBT que estaria prevista para 2019 por conta do processo eleitoral de 2018.

[Temos] Dialogado muito com os Ministérios para pensar que outras ações os outros Ministérios podem fazer ou tem feito. Temos visto algumas experiências positivas no

relatórios referentes à 2014, 2015, 2016 e 2017. Segundo relatado no diálogo, Marina pretende retomar o lançamento desses documentos. Para acessar os relatórios publicados, ver: http://www.mdh.gov.br/assuntos/lgbt/dados-estatisticos. Acesso em: 19 de fevereiro de 2018.

\begin{tabular}{lllllllll}
\hline Vol & 01, & $N$ & 02 & - & Abr.-Jun., & 2018 & ISSN & 2595-3206
\end{tabular}


MDS [Ministério do Desenvolvimento Social], no Ministério da Saúde. Vamos voltar a dialogar com o Ministério da Cultura para retomar algumas pautas que estavam paradas dentro daquele lugar. Então são essas articulações o tempo inteiro. O papel mesmo da Diretoria é esse, articular, tanto a nível nacional, como internacional seja com a América Latina, no Mercosul, ou através da Comissão Interamericana de Direitos Humanos. O tempo inteiro tem que estar respondendo documentos técnicos, construindo essas pautas. E ver o que consegue avançar com a questão do nome social. Hoje o novo desafio é de implementar as resoluções, as decisões e os documentos oficiais dentro do governo.

O PRONATEC LGBT $^{14}$, como um retorno, a questão da profissionalização, isso já é uma demanda que já está lá dentro do Ministério [da Educação], mas a gente precisa articular de que forma vai incluir essas pessoas no programa já que temos a modalidade LGBT, mas de que forma vamos sensibilizar as pessoas envolvidas? Era uma proposta que já tinha sido feita, mas por questões burocráticas do próprio MEC não aconteceram mais... Então estamos retomando agora pra ver se, pelo menos no segundo semestre, conseguiremos incluir alguns grupos ou algumas pessoas dentro desse lugar do PRONATEC.

Cleyton: Você falando, eu lembrei que também compôs o Comitê Técnico de Cultura LGBT do Ministério da Cultura. Poderia resumidamente falar como foi aquela experiência?

Marina: O Comitê era um braço do Ministério para pautar as questões LGBT. Na verdade, eu participei dois anos como conselheira e provocamos algumas ações, inclusive foi realizado o I Encontro de Arte e Cultura LGBT ${ }^{15}$ lá no Rio de Janeiro, onde tivemos nossa participação. Também fomos à TEIA da Diversidade em Natal ${ }^{16}$. Importante é retomar o dialogo com o MinC [Ministério da Cultura] para reativação do

${ }^{14}$ O PRONATEC é a sigla para Programa Nacional de Acesso ao Ensino Técnico e Emprego criado no Governo Dilma.

${ }^{15}$ O I Encontro Nacional de Arte e Cultura LGBT aconteceu em junho de 2014 na cidade de Niterói/RJ. Maiores informações da iniciativa podem ser obtidas em: http://www.cultura.gov.br/noticias-destaques//asset publisher/OiKX3xIR9iTn/content/niteroi-recebe-o-i-encontro-nacional-de-arte-e-culturalgbt/10883. Acesso em: 19 de fevereiro de 2018.

16 A TEIA Nacional da Diversidade ocorreu em maio de 2014 e foi organizado na gestão ministerial de Marta Suplicy no Ministério da Cultura. Para informações mais detalhadas do evento, acessar o site oficial: http://culturadigital.br/teiadadiversidade/. Acesso em: 19 de fevereiro de 2018.

\begin{tabular}{llllll|lll} 
Vol & 01, & $N$ & 02 & - & Abr.-Jun., & 2018 & ISSN & 2595-3206
\end{tabular} http://www.revistas.unilab.edu.br/index.php/rebeh/index 
Comitê e provocar novamente as políticas inclusivas como artistas e de performance LGBT.

\section{Cleyton: Quais são seus planos, desejos e aspirações a médio e longo prazo?}

Marina: Nossa, essa aí é babado! Bom, meus planos, quer dizer, não sabemos o que vai acontecer daqui pra frente. Eu acho que esse ano vai ser um ano tenso e talvez 2019 seja muito mais, mas enfim. Meu plano pessoal é de voltar realmente a estudar, fazer talvez um Doutorado ou pesquisa, fortalecer um pouco mais as pesquisas. Eu acho que aqui é um desafio você estar nesse lugar e, ao mesmo tempo, digamos assim, você não consegue corresponder às demandas que são muito maiores. Mas é como eu sempre digo: é um desafio que foi posto, em algum momento, em algum lugar, por alguma força, enfim, não sei, e que a gente tem que manter esse lugar de luta, de reivindicação, de resistência e penso que esse é o maior desafio de estar aqui. Não sei o que vai acontecer em 2019... Não digo nesse lugar, mas manter esse lugar da pessoa trans que está reivindicando seus espaços e buscar, de alguma forma, conquistar alguma coisa melhor nesse cenário tão difícil que a gente vive hoje, um cenário de violência, um cenário de falta de recursos... Eu digo o cenário brasileiro como um todo, acho que manter, de alguma forma.

Mas o desafio mais pessoal é realmente voltar a estudar, não sei se me qualificar, mas pelo menos é realizar um desejo, até pessoal, posso dizer assim, de voltar praquele lugar da academia, de ocupar os espaços, de invadir os espaços, de chutar porta, de ser respeitada e de certa forma porque você acaba sendo uma referência para muitas pessoas. Então é você manter esse lugar de referência pra fazer com que outras pessoas jovens venham e que ocupem também esses lugares. Penso que essas são, quer dizer, o grande desafio nosso também... Eu lembro quando entrei nesse lugar e hoje eu ouço: "Eu aprendi contigo, vi uma entrevista tua". Você vê muito isso, tu acaba, como diz o próprio Fernando Seffner sendo o adulto de referência ou o referencial para aquelas pessoas que, seja na adolescência ou na fase adulta, tem suas dificuldades, medos, desafios e às vezes não conseguem ter coragem, você acaba sendo aquele norte para aquela pessoa. Acho que isso faz com que eu levante todos os dias, que pense em fazer alguma coisa. Não pra nós, não digo tanto para nós, mas para as que vierem nas próximas gerações. Que a gente vê... Se você parar pra pensar nos anos 80, sempre digo, $\begin{array}{lllllllll}\text { Vol } & 01, & N & 02 & - & \text { Abr.-Jun., } & 2018 & \text { ISSN } & \text { 2595-3206 }\end{array}$ http://www.revistas.unilab.edu.br/index.php/rebeh/index 
jamais a gente poderia sair na rua e eu lembro que eu era adolescente, a gente não podia sair na rua em paz porque você era agredido. Hoje se consegue sair na rua. Por mais violento que seja, por mais dificuldade, mas hoje vemos grupos, coletivos, pessoas de mãos dadas na rua, seja em alguns lugares, pode até levar "coió" como a gente diz né, vai levar o baile, mas é muito mais fácil hoje do que no passado. E isso foi o quê? Foram todas essas movimentações que as pessoas fizeram, antes de nós e agora é nosso dever manter esse lugar e fazer com que a coisa vá mais a frente.

\section{Cleyton: Você gostaria de falar algo que não foi pautado nessa entrevista?}

Marina: À título de educação tivemos um trabalho muito bom por consultoria que foi feita no MEC, isso em 2010, que era uma série de documentários da TV Escola. Foi um convite do professor Marco Antônio Torres para construir uma série sobre educação, sexualidade e gênero. Através do Salto para o Futuro 'Educação e Diversidade Sexual $^{17}$. Olha a data, 2011, mas até hoje tem coisas desse material que ainda se discute e que seria muito interessante pra formação de professores. Isso eu usei muito quando eu fazia formação de professores.

Uma coisa interessante que ficou marcado na minha experiência enquanto professora e enquanto gestora foi dar aula na academia de polícia em Porto Alegre porque a polícia é um lugar difícil de discutir algumas demandas. Então quando eu fui convidada para trazer a pauta de Educação em Direitos Humanos com foco da diversidade sexual também foi interessante porque trabalhei com policiais que estavam entrando na academia, policiais que já eram da academia na formação quando foi o Rio Grande Sem Homofobia e policiais da Polícia Civil, delegados, escrivães, quer dizer, pessoas com anos de experiência na área policial e que em algum momento sentaram para ouvir a trans falar ou a questão da experiência, da vivência, então isso ficou marcado, foi uma experiência muito interessante. Porque até então quem fazia esse trabalho era a Marcelly Malta ${ }^{18}$ anos antes. Ela teve essa experiência lá nos anos 2000, 2001, 2002 e

\footnotetext{
${ }^{17} \mathrm{O}$ produto pode ser acessado aqui: http://www.educadores.diaadia.pr.gov.br/arquivos/File/cadernos_tematicos/salto_futuro_educacao_divers idade sexual.pdf. Acesso em: 19 de fevereiro de 2018.

${ }_{18}$ Marcelly Malta é coordenadora Igualdade - Associação de Travestis e Transexuais do Rio Grande do Sul. Para conhecer sua trajetória individual, acompanhe o vídeo do Projeto História de Vida e Ação Política do Laboratório e Políticas Públicas, Ações Coletivas e Saúde (LAPPACS) em: https://www.youtube.com/watch?v=9g341q0rZO8. Acesso em: 19 de fevereiro de 2018.
}

\begin{tabular}{llllllllll}
\hline Vol & 01, & $N$. & 02 & - & Abr.-Jun., & 2018 & ISSN & 2595-3206
\end{tabular}


depois de 10 anos então eu fui na academia também pra fazer esse trabalho. Isso foi na gestão do Governo Tarso Genro e foi uma experiência muito interessante porque você vê assim o quanto temos lugares que você consegue, mesmo com dificuldades, entrar e ficar nesse lugar.

Eu estava vendo esses dias a reportagem da Thina, lá do Ceará, que faz este trabalho. Saiu até no G1 a reportagem, ela deu entrevista e aparece a foto dela fazendo a formação com policiais ${ }^{19}$, quer dizer, são esses lugares que você vê que é possível desde que haja realmente o interesse desses lugares de trazer a pauta. Foi uma experiência muito rica que vale a pena falar. Acho que basicamente foi isso, não lembro de mais alguma coisa assim.

Eu decidi o ano passado [2017], já em julho do ano passado, começar a resgatar memórias através de entrevistas, documentos e compilar isso tudo num livro. Quem está produzindo esse material é minha sobrinha que é jornalista e que eu ajudei a alfabetizála, quer dizer, eu a alfabetizei quando era professora, alfabetizei sete dos meus dez sobrinhos. Ela é jornalista e mora hoje no Canadá, está fazendo este trabalho de transcrever as minhas histórias em um livro biográfico, mas que tem a ver um pouco com essas trajetórias. Não sei se vai ser biográfico no final, mas a gente vai... A ideia é essa, pensar um livro que tenha essas memórias, que tenha esses registros da infância até hoje, ou um bom tempo da vida... É uma meta também, mas que é uma coisa pessoal, não é nada coletivo.

\section{Cleyton: Espero que nossa entrevista ajude na feitura desse livro.}

Marina: Vai ajudar sim.

\section{Cleyton: Obrigado!}

$19 \mathrm{Na}$ verdade a matéria foi publicada no portal UOL e pode ser conferida no link: https://estilo.uol.com.br/comportamento/noticias/redacao/2018/02/08/fui-perseguida-por-ser-travestihoje-treino-policiais-para-nos-respeitar.htm. Acesso em: 19 de fevereiro de 2018.

\begin{tabular}{lllllllll}
\hline Vol 01, & N. & 02 & - & Abr.-Jun., & 2018 & ISSN & 2595-3206
\end{tabular} 


\section{Notas Finais}

Como dito em determinado momento da entrevista, a Secretaria de Direitos Humanos passou por muitas reestruturações desde o início do Governo Temer. 3 dias após a realização dessa entrevista, a Ministra Luislinda Valois, que nutria um desejo pela criação de uma Secretaria Nacional LGBT, foi exonerada do cargo e a imprensa ${ }^{20}$ anunciou que o Ministério dos Direitos Humanos deverá perder o status de Ministério e tornar-se uma Secretaria dentro do Ministério da Justiça. Nesse contexto, o futuro da Diretoria LGBT é incerto assim como o são as políticas públicas LGBT no Brasil.

\section{Referências}

CAYRES, Domitila Costa. Ativismo institucional e interações Estado-movimentos sociais. Revista Brasileira de Informação Bibliográfica em Ciências Sociais, 82, P. 81-104, 2016.

FEITOSA, Cleyton. Políticas Públicas LGBT e Construção Democrática no Brasil. Curitiba: Appris, 2017.

Recebido em: 17/04/2018

Aceito em: 17/05/2018

20 Notícia em: https://oglobo.globo.com/brasil/luislinda-valois-demitida-do-ministerio-dos-direitoshumanos-22412163. Acesso em: 19 de fevereiro de 2018.

\begin{tabular}{lllllllll}
\hline Vol 01, & N. & 02 & - & Abr.-Jun., & 2018 & ISSN & 2595-3206
\end{tabular}

